\title{
Anthropometrics to Identify Overweight Children at Most Risk for the Development of Cardiometabolic Disease
}

\author{
Corinne A. Labyak \\ University of North Florida, c.labyak@unf.edu \\ David M. Janicke \\ Crystal S. Lim \\ James Colee \\ A.E. Mathews \\ University of Florida
}

Follow this and additional works at: https://digitalcommons.unf.edu/hnut_facpub

Part of the Dietetics and Clinical Nutrition Commons

\section{Recommended Citation \\ Nutrition and Dietetics Faculty Publications. 8. \\ https://digitalcommons.unf.edu/hnut_facpub/8 \\ This Article is brought to you for free and open access by the Department of Nutrition and Dietetics at UNF Digital Commons. It has been accepted for inclusion in Nutrition and Dietetics Faculty Publications by an authorized administrator of UNF Digital Commons. For more information, please contact Digital Projects. \\ (C) 2013 All Rights Reserved}

Labyak, Corinne A.; Janicke, David M.; Lim, Crystal S.; Colee, James; and Mathews, A.E., "Anthropometrics to Identify Overweight Children at Most Risk for the Development of Cardiometabolic Disease" (2013).

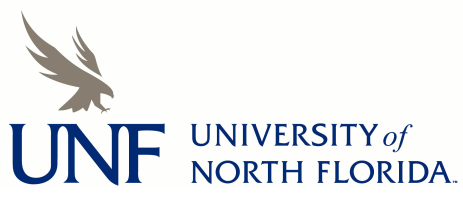




\section{Anthropometrics to Identify Overweight Children at Most Risk for the Development of Cardiometabolic Disease}

Corinne A. Labyak, PhD, RD, LD/N, David M. Janicke, PhD, Crystal S. Lim, PhD, James Colee, and Anne E. Mathews, PhD, RD

\begin{abstract}
Background. Sagittal abdominal diameter (SAD) is a novel anthropometric that correlates more strongly with visceral adipose tissue (VAT) and cardiometabolic disease risk in adults compared with body mass index (BMI). However, little research has evaluated this measurement in children. Objective. To evaluate $S A D$ as a measure of cardiometabolic risk compared with other anthropometrics in overweight/obese children. Methods. This study was a cross-sectional subset analysis of 8- to 12-year-old overweight/ obese children. SAD was compared to BMI, waist circumference (WC), BMI z-score, and percent body fat to determine which measurement was most closely associated with cardiometabolic risk factors. A total cardiometabolic risk score comprising all biochemical markers and blood pressure was also compared to these same anthropometrics. Results. Overweight/obese children ( $n=145$, mean age $10 \pm 1.4$ years, mean BMI percentile $97.9 \pm 0.02$ ) were included in the analysis. SAD correlated with the greatest number of biochemical markers/blood pressure values including triglycerides $(\mathrm{r}=.18, \mathrm{P}=.03)$, HgbA1c $(\mathrm{r}=.21, \mathrm{P}=.01)$, and systolic blood
\end{abstract}

\begin{abstract}
pressure $(\mathrm{r}=.38, \mathrm{P}<.0001)$. SAD was more strongly correlated to total risk score $(\mathrm{r}=.25, \mathrm{P}=.002)$ than $W C(\mathrm{r}=$ $.22, \mathrm{P}=.006), B M I(\mathrm{r}=.17, \mathrm{P}=.04)$, $B M I-\mathrm{z}(\mathrm{r}=.18, \mathrm{P}=.03)$, and percent body fat $(\mathrm{r}=.18, \mathrm{P}=.03)$. Conclusion. This is the first study to evaluate $S A D$ in overweight/obese American children as a marker of cardiometabolic disease
\end{abstract}

( hildhood obesity is a major national public health concern. Seventy percent of obese teenagers develop into obese adults. ${ }^{1}$ Obesity during childhood is associated with the development of insulin resistance, diabetes, and cardiovascular disease (CVD) throughout the lifecycle. ${ }^{2}$ Increased visceral adipose tissue (VAT),

\section{"Obesity during childhood is associated with the development of insulin resistance, diabetes, and cardiovascular disease throughout the lifecycle."}

risk. The results suggest a slightly stronger correlation between $S A D$ and cardiometabolic risk factors in overweight/obese children; however, all correlations were weak. As this was a pilot study, additional research is needed prior to recommending the use of this measurement in clinical practice.

Keywords: sagittal abdominal diameter; children; adolescents; overweight and obesity; cardiometabolic disease in particular, has been identified as increasing an individual's risk in the development of these obesity-related cardiometabolic diseases. Excess VAT is hypertrophied, dysfunctional intraabdominal tissue that is hyperlipolytic, leading to the release of free fatty acids directly into the liver and contributing to alterations in glucose metabolism and insulin resistance. ${ }^{3}$ Also, VAT acts as a remarkable endocrine organ secreting proinflammatory cytokines such as tumor necrosis factor- $\alpha$ and interleukin- 6 and

DOI: 10.1177/1941406413501379. From the Food Science and Human Nutrition Department (CAL, AEM), the Department of Nutrition and Dietetics (DMJ, CSL), and the Department of Statistics (JC), University of North Florida, Jacksonville, Florida. Address correspondence to Anne E. Mathews, PhD, RD, Food Science and Human Nutrition Department, University of Florida, P0 Box 110370, Gainesville, FL 32611-0370; e-mail: anne.mathews@ufl.edu.

For reprints and permissions queries, please visit SAGE's Web site at http://www.sagepub.com/journalsPermissions.nav.

Copyright (C) 2013 The Author(s) 
has been associated with elevated C-reactive protein levels. ${ }^{4}$ These mechanisms all contribute to the proinflammatory environment that VAT promotes in the development of type 2 diabetes and CVD.

The association between childhood obesity and increased risk for the development of cardiometabolic diseases potentiates the need to identify easy, inexpensive, and reliable methods to identify those at most risk. Common anthropometric measurements used to identify obesity are body mass index (BMI) and waist circumference (WC); however, there is growing evidence suggesting that a newer measurement, sagittal abdominal diameter (SAD), can more accurately identify adults most at risk by more precisely measuring VAT. Multiple studies have examined the relationship between $\mathrm{SAD}$ and other measures of obesity and risk factors for cardiometabolic disease in adults. ${ }^{5-18}$ However, only 5 known studies have been conducted in children, all of which were completed outside the United States. ${ }^{19-22}$ Therefore, the purpose of this project was to examine the relationship between SAD and cardiometabolic risk factors in 8- to 12-year-old overweight and obese children, with the goal of adding to the dearth of data in this field.

\section{Methods}

\section{Study Design}

This study is a cross-sectional subset analysis of participants enrolled in the Extension Family Lifestyle Intervention Project (E-FLIP for Kids) that was approved by the University of Florida's Institutional Review Board. E-FLIP for Kids is a prospective, randomized, behavioral lifestyle intervention with 8- to 12-year-old overweight and obese children and their parents in rural communities in North Central Florida. The methods of the overall project can be found in Contemporary Clinical Trials. ${ }^{23}$

\section{Participants}

Participants included in this analysis were a subset of 8- to 12-year-old overweight/obese children. Children were enrolled in 4 different waves from April 2010 to February 2012. SAD was not measured in the first wave and therefore these children were not included in this analysis. The sample size for this study was determined by the major outcomes of the E-FLIP for Kids study, which included change in BMI- $z$ score from baseline to postintervention. However, in conducting our literature review, studies of similar size found significant correlations between anthropometric measurements and disease risk factors. ${ }^{19,24}$

\section{Measures}

The following measurements were taken by trained staff prior to beginning the intervention. Measurements were taken in the afternoon and not in the fasted state. Height was measured in triplicate using a portable Harpendon stadiometer to the nearest $0.1 \mathrm{~cm}$. Weight was measured to the nearest $0.1 \mathrm{~kg}$ in triplicate using a portable, digital scale (Tanita BWB-800) and percent body fat was measured in triplicate using a bioelectrical impedance certified digital scale (Tanita Body Composition Monitor BC-533). The Tanita BC-533 was created for use in community settings and has a child specific mode, which takes into account child's weight, height, age, and gender to ensure accurate measurements. The Tanita BC-533 has been shown to be safe and effective and has been used in previous research examining body fat percentage in youth. ${ }^{25}$ The child's BMI was calculated and plotted on the appropriate Centers for Disease Control and Prevention growth chart for age and gender to obtain BMI percentile ranking. BMI- $z$ score was calculated by taking into account a child's age, sex, BMI, and a reference standard for children's age and sex. WC was measured in triplicate with a tape measure at the top of the ileac crest to the nearest $0.1 \mathrm{~cm}$. SAD was measured in triplicate to the nearest $0.1 \mathrm{~cm}$ in the supine position at the top of the iliac crest with a Holtain Kahn caliper. Children were told to take a deep breath, exhale, and relax. The top bar of the caliper was then pushed down to just touching the top of the stomach.
Blood measures were assessed by taking 2 to 3 drops of blood from the child's finger under aseptic conditions. The Alere Cholestech LDX (Alere, Inc, Waltham, MA), point of service machine, was used to determine total and low-density lipoprotein (LDL) cholesterol, and triglycerides. The Alere Cholestech GDX A1c point of service machine (Alere, Inc) was used to measure HgbA1c. Blood pressure was taken by a nurse after the child rested for 15 minutes in a sitting position with an appropriately sized manual blood pressure cuff according to methods described by Williams et al. ${ }^{26}$ Blood pressure was taken 3 times with 2 minutes between each measurement. The first measurement was discarded, and the last 2 measurements were averaged. To create a "total risk score" for each participant, the methods were adapted from Ohrvall et $\mathrm{al}^{17}$; each metabolic risk measure was standardized to a mean of 0 and a variance of 1 . The sum of total and LDL cholesterol, triglycerides, systolic blood pressure (SBP), diastolic blood pressure (DBP), and HgbA1c values minus the high-density lipoprotein cholesterol (HDL-C) value yielded the total risk score.

\section{Statistical Analyses}

All data were analyzed using JMP 8.0 Statistical Software (SAS Inc, Cary, NC). Regression analysis was used in analyzing the association of all the anthropometric measurements and laboratory values. Descriptive statistics are reported as mean \pm standard deviation. A $P$ value of $<.05$ was considered significant.

Spearman's correlation analysis was conducted fitting SAD, WC, percent body fat, BMI, and BMI- $z$ against the disease risk values of total cholesterol, HDL and LDL cholesterol, triglycerides, SBP, DBP, and HgbA1c at baseline. Spearman's correlation analysis was also used to compare the baseline anthropometric measurements with total risk score. The SAD value that correlated with the median total risk score of 0 was determined and children were categorized as falling above or below this value. 


\section{Table 1.}

Characteristics of Participants at Baseline.

\begin{tabular}{|l|c|c|}
\hline & $\mathrm{n}=145$ & Percentage of Total \\
\hline Females & 83 & 57 \\
\hline Males & 62 & 43 \\
\hline Age at enrollment & & 3 \\
7 Years & 19 & 13 \\
8 Years & 34 & 23 \\
8 Years & 30 & 21 \\
10 Years & 30 & 21 \\
11 Years & 28 & 19 \\
12 Years & 102 & 70 \\
\hline Racial group & 17 & 12 \\
White & 18 & 13 \\
Black & 4 & 3 \\
Biracial & 13 & 89 \\
Unknown & 129 & 9 \\
\hline Ethnic group & & \\
Non-Hispanic & & \\
Hispanic & & \\
No response & & \\
\hline
\end{tabular}

\section{Results}

One hundred and eighty-nine children met the eligibility criteria and were enrolled in waves 2,3 , and 4 of the E-FLIP for Kids study. Forty-four children were excluded from the analysis due to lacking a component of the anthropometric or blood measures, leaving a sample size of 145 children. Parents identified the race and ethnicity of participating children as Caucasian (70\%), black (12\%), biracial (12\%), and unknown (3\%). Nine percent of this group was Hispanic, 89\% non-Hispanic. There was an even distribution among each age group from 8 to 12 years, ranging from $13 \%$ to $23 \%$ per age group (Table 1).

\section{Anthropometric and Biochemical Data}

Baseline anthropometric and biochemical data from the 145 participants are presented in Table 2. Eight percent of the children fell into the overweight range of 85 th to $<95$ th percentile BMI, with the remaining $92 \%$ in the $\geq 95$ th percentile BMI range, classifying them as obese. Fifty-two percent of the children classified as obese were at or above the 99th percentile for age and gender. The mean BMI of the children at baseline was $29 \pm$ $5.3 \mathrm{~kg} / \mathrm{m}^{2}$, which by adult standards would categorize them as being overweight. Furthermore, the mean WC in our study was $92 \pm 12.8 \mathrm{~cm}$. This mean WC is above the 90th percentile for 8- to 12-year-old children, which ranges from 67.8 to $84.8 \mathrm{~cm}$ depending on age and gender. ${ }^{27}$

While individual children (85.5\%) had biochemical and/or blood pressure values that were out of the normal range, when evaluating all children together, only the mean triglyceride and HDL cholesterol levels were abnormal. The mean triglyceride level of children at baseline was $164 \pm 75 \mathrm{mg} / \mathrm{dL}$, which exceeds the recommended level for this age group. The mean HDL-C of $38 \pm 9$ $\mathrm{mg} / \mathrm{dL}$ is below the recommended level of $>45 \mathrm{mg} / \mathrm{dL}$ for children and adolescents. With a mean WC of $92 \pm 13$ $\mathrm{cm}$ along with abnormal triglyceride and HDL-C levels, over half of these children (54\%) met the criteria for metabolic syndrome as categorized by Cook et al. ${ }^{28}$

\section{Correlations of Individual Anthropometric Measures With Disease Risk Factors}

Significant correlations among anthropometric values and biochemical markers were detected, although the number and strength of these correlations differed (Table 3). As hypothesized, SAD correlated positively with more markers of disease risk and to a greater degree than other anthropometric measures including triglycerides $(r=.18, P=.03)$, HgbA1c $(r=.21, P=.01)$ and $\operatorname{SBP}(r=.38, P \leq$ $.0001)$. WC correlated positively with $\operatorname{SBP}(r=.34, P \leq .0001)$ and DBP $(r=$ $.21, P=.01)$. BMI- $z$ correlated positively with triglycerides $(r=.17, P=.04)$ and SBP $(r=.28, P \leq .007)$. BMI correlated positively with HgbA1c $(r=.17, P=.04)$ and SBP $(r=.37, P \leq .0001)$, and percent body fat correlated positively with SBP $(r=.32, P=.0001)$.

\section{Total Risk Score Evaluated at Baseline}

As predicted, some anthropometric measures correlated with some biochemical markers of risk and other anthropometric measures correlated with other risk factors. Thus, we conducted an exploratory analysis to further evaluate the relationship between the various 


\section{Table 2.}

Mean (Standard Deviation) of Anthropometric Measurements and Biochemical Markers/Blood Pressure of Participants at Baseline $(n=145)$.

\begin{tabular}{|c|c|c|}
\hline & All Participants & Recommended Values \\
\hline \multicolumn{3}{|l|}{ Anthropometric data } \\
\hline Weight (lbs) & $142.3(40.5)$ & \\
\hline Height (in.) & $58.7(3.9)$ & \\
\hline BMI & $29(5)$ & \\
\hline BMI percentiles & $98(2)$ & $<85$ th percentile for age and gender \\
\hline BMI-Z & $2.18(0.4)$ & \\
\hline WC (cm) & $92(13)$ & $<90$ th percentile age and gender \\
\hline Percent body fat & $40(7)$ & Unknown \\
\hline $\mathrm{SAD}(\mathrm{cm})$ & $21.14(3.2)$ & Unknown \\
\hline \multicolumn{3}{|c|}{ Biochemical markers and blood pressure } \\
\hline Triglycerides (mg/dL) & $164(75)$ & $0-9$ years $<75 ; 10-19$ years $<90$ \\
\hline Total cholesterol (mg/dL) & $159(34)$ & $<170$ \\
\hline HDL cholesterol (mg/dL) & $38(9)$ & $>45$ \\
\hline LDL cholesterol (mg/dL) & $88(29)$ & $<110$ \\
\hline $\operatorname{HgbA1C}(\mathrm{mg} / \mathrm{dL})$ & $5.48(0.3)$ & \\
\hline $\mathrm{SBP}(\mathrm{mm} \mathrm{Hg})$ & $96(10)$ & $<90$ th percentile for age/gender/height \\
\hline $\mathrm{DBP}(\mathrm{mm} \mathrm{Hg})$ & $64(7)$ & $<90$ th percentile for age/gender/height \\
\hline MetS $(\%)$ & 54 & \\
\hline Total risk score & $-2.14(3.8)$ & \\
\hline
\end{tabular}

Abbreviations: BMI, body mass index; WC, waist circumference; SAD, sagittal abdominal diameter; HDL, high-density lipoprotein; LDL, low-density lipoprotein; SBP, systolic blood pressure; DBP, diastolic blood pressure.

anthropometric measures and overall disease risk. Compared to other anthropometric measurements, $\mathrm{SAD}(r=$ $.25, P=.002)$ was most strongly correlated with the total risk score (Table 4).

An exploratory aim of this study was to determine if there was a cutoff point at which SAD correlated with cardiometabolic risk in overweight and obese children. A cutoff value of approximately $21 \mathrm{~cm}$ in both sexes correlated with a risk score greater than the median total risk score of 0 in the 145 participants.

\section{Discussion}

As hypothesized, SAD was found to significantly correlate with the greatest number of markers of disease risk and correlated the most strongly compared with other anthropometric measures ( $r=$ $.25, P=.002)$ to total cardiometabolic risk in this population of overweight and obese children. The national childhood obesity epidemic compels the need to ascertain the most reliable, easy, and inexpensive anthropometric measurements that can be used to identify children who are most at risk for chronic disease. SAD has been found to be valid and reliable ${ }^{29}$ and may be an ideal measurement to consider because it has been shown to most closely correlate with visceral adiposity compared with other anthropometric measurements in adult populations. ${ }^{30,31}$ This is significant because visceral adiposity is more indicative of the disease risk associated with obesity than subcutaneous fat. This is the first known study to evaluate the associations between SAD in overweight/obese American children with 


\section{Table 3.}

Correlation Between Anthropometric Measurements and Biochemical Markers/Blood Pressure at Baseline. ${ }^{a}$

\begin{tabular}{|c|c|c|c|c|c|c|c|c|c|c|}
\hline \multirow[b]{2}{*}{$\begin{array}{l}\text { Biochemical Marker/Blood } \\
\text { Pressure }(n=145)\end{array}$} & \multicolumn{2}{|c|}{$\operatorname{SAD}(\mathrm{cm})$} & \multicolumn{2}{|c|}{ WC (cm) } & \multicolumn{2}{|c|}{ Body Fat (\%) } & \multicolumn{2}{|c|}{ BMI } & \multicolumn{2}{|c|}{ BMI-Z } \\
\hline & $r$ & $P$ & $r$ & $P$ & $r$ & $P$ & $r$ & $P$ & $r$ & $P$ \\
\hline Triglycerides (mg/dL) & .18 & .03 & .14 & .10 & .07 & .37 & .12 & .15 & .17 & .04 \\
\hline Cholesterol (mg/dL) & .01 & .90 & -.02 & .84 & -.11 & .20 & -.08 & .32 & -.03 & .74 \\
\hline HDL cholesterol (mg/dL) & -.12 & .16 & -.15 & .07 & -.11 & .21 & -.15 & .08 & -.13 & .12 \\
\hline LDL cholesterol (mg/dL) & -.04 & .63 & -.06 & .47 & -.12 & .15 & -.11 & .19 & -.08 & .36 \\
\hline $\operatorname{HgbA1c}(\mathrm{mg} / \mathrm{dL})$ & .21 & .01 & .15 & .06 & .09 & .27 & .17 & .04 & .16 & .06 \\
\hline $\mathrm{SBP}(\mathrm{mm} \mathrm{Hg})$ & .38 & $<.0001$ & .34 & $<.0001$ & .32 & .0001 & .37 & $<.0001$ & .28 & .0007 \\
\hline $\mathrm{DBP}(\mathrm{mm} \mathrm{Hg})$ & .12 & .14 & .21 & .01 & .11 & .20 & .06 & .46 & .04 & .62 \\
\hline
\end{tabular}

Abbreviations: BMI, body mass index; WC, waist circumference; SAD, sagittal abdominal diameter; HDL, high-density lipoprotein; LDL, low-density lipoprotein; SBP, systolic blood pressure; DBP, diastolic blood pressure.

${ }^{a} r=$ correlation coefficients; $P \leq .05$ is significant.

\section{Table 4.}

Spearman's Correlations Between SAD, WC, Percent Body Fat, BMI, and BMI- $z$ With Total Risk Score at Baseline $(\mathrm{n}=145)^{\mathrm{a}}$. $(\mathrm{r}=$ correlation coefficients; $P$ value $\leq .05$ is significant).

\begin{tabular}{|l|c|c|}
\hline $\begin{array}{l}\text { Anthropometric } \\
\text { Measure }\end{array}$ & $r$ & $P$ \\
\hline Total risk score & & \\
\hline BMl- $z$ & .17 & .03 \\
\hline WC & .23 & .006 \\
\hline Body fat & .12 & .15 \\
\hline SAD & .25 & .002 \\
\hline BMl & .17 & .04 \\
\hline
\end{tabular}

Abbreviations: BMI, body mass index; WC, waist circumference; SAD, sagittal abdominal diameter.

${ }^{\mathrm{a}} r=$ correlation coefficients; $P \leq .05$ is significant.

cardiometabolic risk factors. A recent study by Al-Daghri et a ${ }^{32}$ identified SAD cutoff values in 964,5 to 17 year olds in
Saudi Arabia by comparing SAD values with other measures of obesity (including BMI, WC, and hip circumference). Based on their results, the researchers suggest using the following values as indicators of obesity as measured by SAD: $14 \mathrm{~cm}$ for prepubertal boys and girls; $15 \mathrm{~cm}$ and $16 \mathrm{~cm}$ for pubertal girls and boys, respectively; and $21.5 \mathrm{~cm}$ and $22 \mathrm{~cm}$ for postpubertal girls and boys, respectively. ${ }^{32}$ While we were unable to categorize children as prepubertal, pubertal, or postpubertal, $21 \mathrm{~cm}$ appears to be an upper limit associated with a higher degree of cardiometabolic disturbance.

Our study included 145 overweight and obese children, between the ages of 8 and 12. In this population, SAD correlated the most strongly with accepted markers of cardiometabolic disease. As all correlations of anthropometrics were weak, the significance of this finding and application to clinical practice should be viewed with caution at this time. Future studies should evaluate SAD in children across the weight spectrum and evaluate what measurement is the most acceptable to both children and health care providers. Age- and gender-specific ranges of $\mathrm{SAD}$ that are related to cardiometabolic risk must also be determined to make this a clinically valuable measurement

\section{Acknowledgments}

We thank the Cooperative Extension Services faculty/ staff, the participating children, and parents in this trial; the funding support from the $\mathrm{NHH}$ that made this trial possible.

\section{Author Note}

This study is supported by a grant from the National Institute for Diabetes and Digestive and Kidney Diseases (R18 DK082374-01; PI: David M. Janicke). The author(s) declared no potential conflicts of interest with respect to the research, authorship, and/ or publication of this article

\section{References}

1. Zhao J, Grant SF. Genetics of childhood obesity. J Obes. 2011;2011:845148. doi:10.1155/2011/845148.

2. Allcock DM, Gardner MJ, Sowers JR Relation between childhood obesity and adult cardiovascular risk. Int $J$ Pediatr Endocrinol. 2009;2009:108187. doi:10.1155/2009/108187.

3. Despres JP, Lemieux I. Abdominal obesity and metabolic syndrome. Nature. 2006; 444:881-887 
4. Després JP, Lemieux I, Bergeron J, et al. Abdominal obesity and the metabolic syndrome: contribution to global cardiometabolic risk. Arterioscler Thromb Vasc Biol. 2008;28:1039-1049.

5. Nakata K, Choo J, Hopson MJ, et al. Stronger associations of sagittal abdominal diameter with atherogenic lipoprotein subfractions than waist circumference in middle-aged US white and Japanese men. Metabolism. 2010;59:1742-1751.

6. Vasques AC, Rosado LE, Rosado GP, et al. Different measurements of the sagittal abdominal diameter and waist perimeter in the prediction of HOMA-IR. Arq Bras Cardiol. 2009:93:511-518.

7. Vasques AC, Rosado L, Rosado G, Ribeiro Rde C, Franceschini S, Geloneze B. Anthropometric indicators of insulin resistance. Arq Bras Cardiol. 2010;95: e14-e23.

8. Vasques AC, Rosado LE, Rosado GP, et al. Predictive ability of anthropometric and body composition indicators in the identification of insulin resistance. Arq Bras Endocrinol Metabol. 2009;53:72-79.

9. Risérus U, Arnlöv J, Brismar K, Zethelius B, Berglund L, Vessby B. Sagittal abdominal diameter is a strong anthropometric marker of insulin resistance and hyperproinsulinemia in obese men. Diabetes Care. 2004;27:2041-2046.

10. Cui H, Kolm P, Phillips LS. Sagittal abdominal diameter is better than waist circumference or BMI in identifying diabetes. American Diabetes Association; 2008 (Abstract 992-P). http://professional. diabetes.org/Abstracts_Display. aspx?TYP=1\&CID=70013. Accessed July 31, 2013.

11. Anjana M, Sandeep S, Deepa R, Vimaleswaran KS, Farooq S, Mohan V. Visceral and central abdominal fat and anthropometry in relation to diabetes in Asian Indians. Diabetes Care. 2004;27:2948-2453.

12. Valsamakis G, Chetty R, Anwar A, Banerjee AK, Barnett A, Kumar S. Association of simple anthropometric measures of obesity with visceral fat and the metabolic syndrome in male Caucasian and Indo-Asian subjects. Diabet Med. 2004;21:1339-1345.

13. Pimentel GD, Moreto F, Takahashi MM, Portero-McLellan KC, Burini RC. Sagittal abdominal diameter, but not waist circumference is strongly associated with glycemia, triacilglycerols and HDL-C levels in overweight adults. Nutr Hosp. 2011;26:1125-1129.

14. Stevens J, McClain JE, Truesdale KP. Selection of measures in epidemiologic studies of the consequences of obesity. Int J Obes (Lond). 2008;32(suppl 3):S60S66.

15. Petersson H, Daryani A, Risérus U. Sagittal abdominal diameter as a marker of inflammation and insulin resistance among immigrant women from the Middle East and native Swedish women: a crosssectional study. Cardiovasc Diabetol. 2007;6:10.

16. Smith DA, Ness EM, Herbert R, et al. Abdominal diameter index: a more powerful anthropometric measure for prevalent coronary heart disease risk in adult males. Diabetes Obes Metab. 2005;7:370-380

17. Ohrvall M, Berglund L, Vessby B. Sagittal abdominal diameter compared with other anthropometric measurements in relation to cardiovascular risk. Int J Obes Relat Metab Disord. 2000;24:497-501.

18. Iribarren C, Darbinian JA, Lo JC, Fireman $\mathrm{BH}, \mathrm{Go}$ AS. Value of the sagittal abdominal diameter in coronary heart disease risk assessment: cohort study in a large, multiethnic population. Am J Epidemiol. 2006;164:1150-1159.

19. Larsson C, Hernell O, Lind T. Moderately elevated body mass index is associated with metabolic variables and cardiovascular risk factors in Swedish children. Acta Paediatr. 2011;100:102-108.

20. Hlavatý $\mathrm{P}$, Zamrazilová H, Kunesová M, Dusátková L, Sedlácková B, Hainer $\mathrm{V}$. Reduction of abdominal obesity and cardiometabolic health risks in obese adolescents in response to a short-term spa weight management program. Cas Lek Cesk. 2010;149:537-541.

21. Owens S, Litaker M, Allison J, Riggs S, Ferguson M, Gutin B. Prediction of visceral adipose tissue from simple anthropometric measurements in youths with obesity. Obes Res. 1999;7:16-22.

22. Al-Attas OS, Al-Daghri NM, Alokail MS, et al. Association of body mass index, sagittal abdominal diameter and waist-hip ratio with cardiometabolic risk factors and adipocytokines in Arab children and adolescents. BMC Pediatr. 2012;12:119.

23. Janicke DM, Lim CS, Perri MG, et al. The Extension Family Lifestyle Intervention Project (E-FLIP for Kids): design and methods. Contemp Clin Trials. 2011;32 50-58.

24. Asayama K, Dobashi K, Hayashibe H, et al. Threshold values of visceral fat measures and their anthropometric alternatives for metabolic derangement in Japanese obese boys. Int J Obes Relat Metab Disord. 2002;26:208-213.

25. Denova-Gutiérrez E, Jiménez-Aguilar A, Halley-Castillo E, et al. Association between sweetened beverage consumption and body mass index, proportion of body fat and body fat distribution in Mexican adolescents. Ann Nutr Metab. 2008;53: 245-251.

26. Williams CL, Hayman LL, Daniels SR, et al. Cardiovascular health in childhood: a statement for health professionals from the Committee on Atherosclerosis, Hypertension, and Obesity in the Young (AHOY) of the Council on Cardiovascular Disease in the Young, American Heart Association. Circulation. 2002;106: 143-160.

27. Fernández JR, Redden DT, Pietrobelli A Allison DB. Waist circumference percentiles in nationally representative samples of African-American, European-American, and Mexican-American children and adolescents. J Pediatr. 2004;145:439-444.

28. Cook S, Auinger P, Li C, Ford ES. Metabolic syndrome rates in United States adolescents, from the National Health and Nutrition Examination Survey, 1999-2002. J Pediatr. 2008;152:165-170.

29. Sampaio LR, Simões EJ, Assis AM, Ramos LR. Validity and reliability of the sagittal abdominal diameter as a predictor of visceral abdominal fat. Arq Bras Endocrinol Metabol. 2007;51:980-986.

30. Yim JY, Kim D, Lim SH, et al. Sagittal abdominal diameter is a strong anthropometric measure of visceral adipose tissue in the Asian general population. Diabetes Care. 2010;33:2665-2670.

31. Snijder MB, Visser M, Dekker JM, et al. The prediction of visceral fat by dual-energy $\mathrm{X}$-ray absorptiometry in the elderly: a comparison with computed tomography and anthropometry. Int J Obes Relat Metab Disord. 2002;26:984-993.

32. Al-Daghri N, Alokail M, Al-Attas O, Sabico S, Kumar S. Establishing abdominal height cut-offs and their association with conventional indices of obesity among Arab children and adolescents. Ann Saudi Med. 2010;30:209-214. 